\title{
The emergence of climate change adaptation as a new field of public policy in Europe
}

\author{
Eric Massey • Dave Huitema
}

Received: 3 February 2014/ Accepted: 9 February 2015/Published online: 24 February 2015

(C) The Author(s) 2015. This article is published with open access at Springerlink.com

\begin{abstract}
Over the past decade, climate change adaptation has become an integral item on the climate policy agendas of several European countries. As such, researchers have begun to question what concrete changes in polices are occurring at national levels and what dynamics can explain these changes. While new laws, policies and institutions have been created to deliver adaptation, supported through processes of cross-national policy innovation and learning, another interesting observation being made is that adaptation is steadily emerging into a new separate and distinct policy field in a handful of countries. The purpose of this article is twofold: first, to empirically map where and to what degree adaptation is emerging as a policy field; second, to theoretically and empirically explore the drivers underpinning policy field emergence. Based upon a survey of leading adaptation policy makers in 27 European countries, we show that there are signs of adaptation becoming a policy field in 15 countries. Furthermore, we find that even though institutional change, coupled with increasing public attention and
\end{abstract}

Editor: James D. Ford.

Electronic supplementary material The online version of this article (doi:10.1007/s10113-015-0771-8) contains supplementary material, which is available to authorized users.

E. Massey $(\bowtie) \cdot$ D. Huitema

Institute for Environmental Studies, VU University Amsterdam,

De Boelelaan 1087, 1081 HV Amsterdam, The Netherlands

e-mail: e.e.massey@vu.nl

D. Huitema

e-mail: d.huitema@vu.nl

D. Huitema

Faculty of Management, Science and Technology, Open

University of the Netherlands, Heerlen, The Netherlands pressure on governments to react to climate change, has helped drive the emergence of adaptation as a policy field, it would appear that it is the activities of elite policy makers and experts that have had the most influence.

Keywords Climate change adaptation - Public policy . Policy fields $\cdot$ EU climate policy $\cdot$ Adaptation

\section{Introduction}

Over the past decades, the topic of policy change has received considerable attention. Moreover, it could be argued that some of the most important theoretical frameworks in the policy science literature, such as the advocacy coalition framework (Sabatier 2007), the punctuated equilibrium framework (Baumgartner and Jones 2009), and the multiple streams framework (Kingdon 1984), have largely focused on understanding such change (Real-Dato 2009). One plank of the argument in that literature is that policy change comes in different sizes and shapes: Some changes are incremental; others are more fundamental and some could be even called paradigmatic (Hall 1993). Interestingly, however, much of the academic debate over policy change takes an important part of the context-the policy field (policy domain, policy monopoly, policy subsystem, policy area) in which such changes occur-as a given. For instance, the advocacy coalition framework focuses on "subsystems" of the broader policy landscape, such as environmental policy (Dryzek and Dunleavy 2009), but not on the formation of these subsystems. The multiple streams framework looks at the separate dynamics within a field (be it transport, education or environment), determining how they have influenced policy change. And analyses of policy change through a punctuated equilibrium framework lens 
also looks at sudden changes inside established policy fields such as energy (Colgan et al. 2011).

The lack of attention paid to policy fields as a whole is not restricted to the leading models of policy sciences. Reviewing a number of textbooks and handbooks on public policy, we find that the term "policy field" is essentially taken for granted; while frequently used, it is rarely defined or treated as a relevant variable in understanding policy dynamics. As a result, a crucial level of analysis for policy change is missing. This is remarkable because, as Massey et al. (2014) state, "policy fields represent the highest form of state and citizen regulatory and governing capacity over a particular topic..." (p. 7). Their existence (or absence) has important implications on the type and delivery of public and semipublic goods and the level of attention brought to bear on any public problem (think of topics such as agriculture, health care or education). Additionally, stability is added to the provision of these public goods as policy fields tend to be populated by specialized organizations (e.g., ministries), associated with access and veto points to decision-making processes (e.g., a place at the table during cabinet meetings). Given the consequential role, policy fields play in a governing system coupled with the lack of attention paid to them in the literature (where they come from and how they emerge) opens up a unique opportunity to expand scholarly understanding of policy change.

The purpose of this article is to begin to explore conceptually and empirically how policy fields might emerge at the national level, specifically using the issue of climate change adaptation as a case. We focus on climate change adaptation because, over the past decade, efforts to address the growing impacts of climate change have become a cornerstone of domestic and international climate policy agendas (Ford and King 2013; Bauer et al. 2012; Keskitalo 2010; Neufeldt et al. 2009). Amid the flurry of policy activity, which is especially visible within Europe, researchers have begun to pose questions such as: What concrete changes in polices are occurring at the national level and what can explain these changes (Dupiuis and Biesbroek 2013; Ford et al. 2013)? While new laws have been enacted, new policies implemented, and new institutions created to deliver adaptation, one of the more interesting and perhaps significant observations in policy change is that in the course of this activity, adaptation appears to be steadily emerging into a new separate policy field in a number of European countries (Massey et al. 2014). Such an observation demand we ask: How is this policy change occurring? And what are the forces and dynamics bringing this policy field to life? Since the study of the origins and emergence of policy fields is scant in the policy sciences literature (with the exception of Knoke 2004), our task is both novel and ambitious, conceptually and empirically.
We begin our work at the conceptual level ("A novel framework for studying policy field emergence") by presenting a testable definition of a policy field based on our previous work (see Massey and Huitema 2013; Massey et al. 2014). Then, we develop an original set of potential explanations for the emergence of a policy field-harking back to several conceptual traditions in political science. Highlighting a set of potential factors that might explain their emergence-such elite versus pluralistic activity, and/ or institutional path dependency. In "Results," we turn toward our empirical analysis. Working with the results of an original survey of leading adaptation policy makers in 27 European countries, we first measure the degree to which adaptation is emerging as a policy field in various countries based upon our definition of a policy field. We find that the degree of emergence is quite varied. Following this we test the potential factors for policy field emergence against our dataset. Finally, we analyze whether and how the factors potentially related to the emergence of policy fields have contributed to the varying degrees of adaptation's emergence in our case countries. What we find is that even though institutional change, coupled with increasing public attention and pressure on governments to react to climate change, has helped drive the emergence of adaptation as a policy field, it would appear that it is the activities of elite policy makers and experts that have had the most influence. The article concludes with a discussion of our findings, the limitations of this work and avenues for future research.

\section{A novel framework for studying policy field emergence}

\section{Policy field definition}

While the term policy field and its synonyms policy domain, policy monopoly, policy subsystem, policy area have received limited attention in the literature, a handful of loose descriptions of what they are have been put forth. May et al. (2006) describe them as "established areas of policy that give meaning to common problems and have integrative properties." Borrowing from Laumann and Knoke (1987), Birkland (2011) states that they are "the substantive area of policy over which participants in policy making compete and compromise, such as the environmental policy domain or the health domain." Further, Howlett et al. (2009), Sabatier and Jenkins-Smith (1993) and Baumgartner and Jones (2009) characterize them as a constellation of actors, institutions and ideas within a particular interest sector who put forth problem definitions and solutions for that sector. (For similar descriptions, see also Knoke 2004; Burstein 1991). Massey and Huitema (2013) state, however, that policy fields can be seen as a 
state sanctioned unit of governing within the sociopolitical system of a country where there exist so called "substantive authority," "institutional order" and "substantive expertise" working in tandem to support each other in the management of a public issue or set of related issues (e.g., agriculture, defense, health care). Substantive authority relates to the existence of policy products and outputs such as policy programs, legislation and rules. Institutional order can be seen as the government institutions that produce substantive authority, such as ministries, ministerial offices and parliamentary committees. And substantive expertise is the manifestation of expert knowledge both inside and outside government by people and institutions with a vested interest in a set of particular issues (e.g., policy issue networks, NGOs, think tanks, etc.). What sets this definition apart from its predecessors is that it is the first workable description of a policy field, one that can be used to test for potential policy field existence and emergence.

\section{Conceptual framework}

Having defined a policy field, the remaining questions are how to understand adaptation's emergence conceptually and can such emergence be empirically mapped? To answer these questions, we look at the possible emergence of a policy field through three state-centered political science theoretical lenses: pluralism, elitism and institutionalism. The rationale is as follows. From our reading of the policy science literature, the most dominant theories for explaining policy dynamics and change are the punctuated equilibrium framework, the advocacy coalition framework and the multiple streams framework (see Real-Dato 2009). While these three theories have explanatory capabilities for how public policy works and ultimately changes, their main focus is detailing agenda setting mechanisms and the dynamics of change within existing, well-established policy fields and not how new fields themselves might begin to emerge (Massey and Huitema 2013). Their unit of analysis is a policy issue (e.g., strengthening of environmental regulations, the introduction of green taxes) and not how the field of environmental policy itself emerged. In essence, the study of field emergence goes beyond agenda setting and change. It picks up effectively where these theories end to show how a policy issue can evolve into a field.

Looking outside these dominant theories, attention toward explaining the emergence of new policy fields has received limited attention over the years. Knoke's (2004) work, probably the most well known, attempts to systematically theorize the genesis of new fields. Knoke suggests that six key elements are necessary for a new field to develop-focusing events, technological innovations, political entrepreneurs, issue framing, policy networks and policy domain institutionalization - and explains why each is important to a field's emergence. While he creates a narrative of how these elements fit together, ultimately, he takes an institutionalist perspective for policy field development, arguing that new fields are simply a reconfiguration of previous institutions. By doing so, he ignores the role pluralistic or elitist forces may play. Similarly, policy field emergence is addressed (albeit tangentially) in Williams' (2009) work on the internationalization of Canada's financial services policy. Also writing in the institutionalist vein, he states that new policy fields can emerge when exogenous developments force two or more fields to address a common policy problem in tandem. The result is the creation of what he calls an "uber' policy subsystem" (p. 23, original emphasis, original spelling), where the once separate fields merge to create new institutions and a new assembly of actors to address the problem (see also Jochim and May 2010). Hints of policy field emergence can also be found in recent work on policy innovation (see, for example, Jordan and Huitema 2014; Schaffrin et al. 2014). There, policy field emergence can be seen as a by-product and/or outcome of policy innovation. And, while an interesting finding, these authors also take a decidedly institutionalist approach in explaining policy field emergence, again sidestepping the role other frames might have played.

Given this dearth in the public policy literature, we are forced to expand our horizons and look to broader, more fundamental theories of politics that seek to explain governing processes in sociopolitical systems (i.e., nation states). The justification in exploring the role state-centered theories of governing have played in the emergence of new policy fields is (1) we define policy fields as a unit of governing within the sociopolitical system of a state; (2) a policy field is fundamentally a state or government sponsored set of institutional arrangements to deal with problems and issues in society; and (3) their emergence and creation can be seen as an act of governing by the state and subsequently, without state sanctions they would not exist. In choosing the theoretical lenses the two most immediate to come to mind are pluralism and elitism.

Since the mid-twentieth century, pluralism (see, e.g., Dahl 1967) and elitism (see, e.g., Mills 1956) have become the two dichotomous theories to explain how liberal democratic societies govern themselves, the role political actors play in such societies, and in effect how policy is made or changes. On the one hand, with pluralism the power to enact policy change is diffused (horizontally and vertically) throughout civil society, and despite there being certain power imbalances, access to the policy process remains open to all. On the other hand, with elitism access to the policy process and the power to enact change is portrayed as residing within a closed group of networks, 
cut off from the public, which serve their own political and financial interest. A third lens which can also be explored is institutionalism. Following in the wake of the pluralist vs. elitists discussions, institutionalism (and it variants) has also taken a solid hold in the debate of governance and public policy (Schmidt 2006). Portraying the state/governments, not so much as a constellation of actors working toward some purpose, but rather as a combination or ensemble of institutional arrangements into which political actors are subsumed (Hay et al. 2006). Below we look more in depth at these lenses and conceptually map out how adaptation may have begun to emerge under each.

\section{Pluralism}

One can argue that contemporary pluralism, as complex and multi-veined as it is (see Dryzek and Dunleavy 2009), propounds that while ultimate decision-making authority lies within the components of the state (legislative, executive, judiciary), the ability and the power to shape and influence governing decisions and ultimately policy is spread throughout the polity. In essence, politics and society are divided into multiple actors, interest groups (active and latent) and institutions both inside and outside government (Dahl 1967). Each group having ideas, interests and beliefs on how society should be governed, as well as a valid voice in the governing process. Power and expertise are spread across a variety of institutions which interact and commune with each other. Pluralism stresses the existence of an active civil society which can lobby government through multiple channels and intones the need for dialogue, debate and action. Political decisions are the outcome of a majority of actors or groups reaching consensus on an issue.

Applying a pluralistic lens to the development of adaptation as a policy field, we would expect that it was interest groups within civil society, and perhaps academia that lobbied their governments to expand attention toward adaptation, while battling others who considered the issue less of a priority. We might also postulate that there were organizations with knowledge and expertise about adaptation that recognized the potential gravity of climate change impacts. These organizations initially pushed adaptation on the agenda and continued to lobby government on the need to increase its role and oversight on the issue through the creation of new and codified institutions and authority.

\section{Elitism}

In contrast to the open and inclusive approach to governing that pluralism espouses, elitist theory takes the opposite view stating that political and decision-making power rests with small groups who are removed from those they govern
(Dryzek and Dunleavy 2009). Elites could be political leaders, corporations, wealthy families and those in high society. Through concentration of power and resources, elites can exert their will so as to influence or prevent changes in society. In the modern political science literature, two strains of elite theory have emerged: the "statecraft approach" (Bulpitt 1986a, b) and the "policy communities approach"(Marsh and Rhodes 1992). Under the statecraft approach, policy-making power sits solely in the hands of the state among a small group of top political party officials, civil servants and policy advisors whose goal is to remain in elected office by appearing to make competent policy decisions. On the other hand, policy communities are a small, tight knit group of actors from government, academia, professional organizations and firms that share common interests and values over an issue and have decision-making power over that issue. It should be noted that under elite theory, "policy communities" are distinct entities from the policy networks or issue networks as explained by Howlett, Ramesh and Perl (2009). Where policy communities are decidedly seen as an elite form of governance, policy or issue networks are pluralistic because of their size and diverse membership (Evans 2006). Through sharing respective resources (knowledge, expertise, influence and finances), policy communities are able to materialize their ideas into actions largely with the exclusion of the public or broader government institutions (Evans 2006; Marsh and Rhodes 1992).

Given that elite theory stresses a closed nature to governing, we assume that adaptation, despite being on the agenda, was not a subject of public concern. Specifically, we would expect there to have been a combination of increased governing activity in the realm of adaptation with an absence of discourse on, public demand for, and interest groups around adaptation pushing for its expansion. Similarly, within wider government circles, we would expect to find little activity. Rather there was a policy community of academics, senior politicians and senior managers from economic/social organizations (e.g., insurance companies) with their own knowledge, expertise and mutual interest for adaptation. Within this community, we might find the appearance of reports and academic papers that could be attributed to a handful of authors. On the government side, we might find that emerging regulations, legislation and polices were championed by a limited number of senior officials and that such outputs were in some form ideologically or materially beneficial to just a few economic/social organizations.

\section{Institutionalism}

Unlike pluralism which focuses on the interactions of multiple groups or elitism which traces the actions of a 
limited few, modern institutionalism centers on the institutional landscape and how government and social institutions shape the political and social life. Under this perspective, institutions are not to be thought of as simply administrative organizations but more broadly as also habits and norms of action that individuals and organizations come to adhere to over time, which are stable and enduring in their operation (Goodin 2009). Moreover as Young (2002) states, they are "sets of rules, decisionmaking procedures and programs that define social practices, assign roles to the participants in these practices, and guide interactions among occupants of individual roles" (p. 5). An institutional perspective implies that political and social behavior is structured by relatively stable sets of rules that make behavior predictable and that the types and configurations of institutions define and set parameters for courses of action (Ostrom 1986; Schmidt 2006).

Modern institutional theory can be aggregated along three broad theoretical lines: normative/sociological, rational choice and historical (Lowndes 2002; Schmidt 2006). Because of its eclectic nature and explanatory power, historical institutionalism (HI) is one of the most widely used approaches among institutional scholars (Lowndes 2002; Peters and Pierre 2006). Under HI, institutional patterns of governing operate along routine pathways that persist over long periods of time. New developments can occur only when some form of external pressure is exerted on existing institutional arrangements, such as emerging problems (e.g., climate change impacts) that they do not handle well in the eyes of administrators or the relevant public. As a result, old institutions begin to shift, with new institutions emerging to mitigate the pressure. Paradoxically, this seems to imply that institutions themselves are not the agents behind new institutions but rather responders. Indeed, this lack of identifiable agency has been a source of critique for HI (Peters et al. 2005). This critique, however, might be mitigated under Giddens' (1984) structuration approach. Also central to HI is the concept of path dependence-the notion that previous governing decisions and choices (intentional or not) will roughly determine the boundaries for shaping future decisions and arrangements. The notion of path dependence has two consequences. First, that previous governing decisions might in fact cause future pressures and problems that will spark the development of new institutional arrangements. Second, that path dependence can lead to institutional vestiges whereby any new institutional arrangements will contain elements of the old.

Taking an HI approach, how might we explain the emergence of adaptation as a policy field? Firstly, given the definition of a policy field we might assume that a policy field an institution. Knowing that new institutions stem from existing ones and that the dynamics are brought about by emerging problems and pressures that the old institution could not handle, we might assume that: (1) adaptation would evolve out of previously institutionalized but related policy fields (e.g., climate mitigation policy, land use planning, disaster control or water management); and (2) its emergence was a result of new problem pressures that these fields could not sufficiently resolve. As a result new forms of institutional order, substantive authority and substantive expertise would begin to coalesce around the new problems. Within this new institutional arrangement called adaptation, we would also expect to find vestiges of other policy fields.

While each of these lenses might serve as a plausible explanation for the emergence of a policy field, one critical assumption to be made is that adaptation was already on the public agenda and that is was an existing, established policy issue. Hence, when exploring policy field emergence the key question is as follows: How did it move from being an issue to being a field? Thus as previously mentioned, these theories pick up where previous theories of agenda setting and change have left off.

\section{Methodology}

\section{Survey design and respondent sampling}

The analytical work was based on an original online crossnational survey of 27 European countries. The survey itself was part of a broader project studying the development, innovation and diffusion of climate change adaptation policy making across Europe (see Massey et al. 2014), aiming to collect information and opinions of elite policy makers working firsthand on national level adaptation policy making.

The survey contained 25 questions (in open and closed format) regarding the motivations behind adaptation, barriers to adaptation, its institutional structure and the existence and types of national level policy documents (See ESM1 for a copy of the survey). A particular set of questions was aimed at measuring the degree to which adaptation was a policy field in each country, while another focused on the factors behind its emergence. Respondents were identified from contact lists of European research programs, existing databases, workshop and meeting lists and through personal contacts. For each country, we sought to select between two and five respondents to prevent response bias. In total 106 respondents from 36 European countries were invited to participate in the online survey. In total 53 completed surveys were collected (response $49 \%$ ) from 27 countries (75\% of countries approached). 
Data analysis: an overview

For the data analysis, the following steps were followed. First, based upon the collected data, we calculated a raw policy field score for each country (detailed description follows below). These scores ranged from 0 to 25.2. The raw scores were then normalized on a scale from .000 to 1.000 using the highest raw score 25.2 (UK) as our reference point of 1.000 to derive an overall policy field score (PFS) for each country. ${ }^{1}$ Out of the group of 27 countries, we removed all those that received a PFS of .000 (showing no signs of adaptation as a policy field), thus reducing our dataset to 15 countries. Next we divided and ranked the countries into four groups based upon their PFS: Where countries with a score between .750 and 1.00 were labeled as showing "highly significant" signs of policy field emergence; countries with a score between .500 and .750 as showing "significant" signs of policy field emergence; countries between .250 and .500 as showing "moderate" signs of policy field emergence; and countries with a score higher than .000 but below .250 labeled as showing "limited" signs of policy field emergence. We then analyzed the sample as a whole, based upon the scoring of the survey responses, to see which (if any) of the factors (pluralism, elitism, institutionalism) played a dominant role. Additionally, we performed a regression analysis for each factor on the 15 countries to see what (if any) relation there was between the factors and the degree policy field emergence. We then analyzed each of the four groups, based upon their degree of emergence, in the manner as the entire dataset.

\section{Calculating the policy field scores}

Using our definition of a policy field, in order to measure the potential degree of its emergence requires measuring the degree to which institutional order, substantive authority and substantive expertise are present in a country and provide each country with a total PFS. The score for institutional order (IO) is based on the types and number of national level government institutions devoted to adaptation. Contingent on the types of institutions present (e.g., ministry, ministerial office), a score between .1 and 1 is assigned. These scores are then summed to derive an overall score for IO. The total score for substantive authority (SA) is based on the number of socioeconomic sectors that the national level adaptation legislation, adaptation plans and policy programs cover, with each sector receiving a score of 1 . For example, if the national

\footnotetext{
${ }^{1}$ Previous research shows that adaptation can be considered an emerging policy field in the UK (Massey and Huitema 2013; Contestabile 2014).
}

adaptation program/legislation addressed only agriculture, health and transportation, SA would score a 3 . The overall score of a can range from 1 to $N$. The logic being that a higher score implies more robust SA and therefore a more robust policy field. Substantive expertise (SE) is scored by assigning a score between .1 and 1 based on the types of non-government bodies (e.g., lobby groups, interest groups) that work on adaptation in a country. These are then summed to get an overall SE score. The scores for IO, SA and SE are then summed to derive an overall PFS for a country, with a higher total score representing, for our purposes, evidence of more robust policy field emergence. Scoring data were derived from the survey and then crosschecked against national policy documents. For a detailed methodology, see Massey et al. (2014).

Scoring the theoretical lenses

Given the broad nature of the survey and to avoid "respondent fatigue"(see Ben-Nun 2008), we were only able to quiz respondents on a handful of the factors under each theoretical frame as detailed in Tables 1, 2, 3 above. For each we asked them to rate on a scale of $1-5$ with 1 being "not important at all" and 5 being "very important" how important a particular factor was in contributing to the adoption of adaptation policies. For pluralism, we asked respondents to rate the importance of factors such as increasing public awareness to climate change impacts, pressure from NGO's and pressures from civil society. For elitism, we asked them to rate issues such as internal political pressure from senior political authorities and senior ministries or offices. For institutionalism, we asked them to rate the effectiveness of previous institutions in dealing with adaptation, the idea that adaptation might be more effective with new institutions, and the country's tendency to create new institutions. The aggregate of the responses from each country were then scored and ranked.

\section{Results}

Measuring the degree of policy fields

Of the 27 countries surveyed, 15 showed a PFS above zero. $^{2}$ The results are presented in Table 4 below.

Looking at the results, not only do we find evidence that adaptation is emerging as a policy field in a number of countries, we also see that the degree of its emergence,

\footnotetext{
${ }^{2}$ Countries with a score of 0 (i.e., showing no signs of adaptation as a policy field) include the following: Albania, Bosnia-Herzegovina, Bulgaria, Cyprus, Czech Republic, Estonia, Greece, Iceland, Ireland, Italy, Slovakia and Slovenia.
} 
Table 1 Assumptions and possible evidence for the growth of adaptation policy through Pluralism

\begin{tabular}{|c|c|}
\hline Assumptions & Possible evidence \\
\hline \multicolumn{2}{|l|}{ Pluralism } \\
\hline $\begin{array}{l}\text { Civil society organizations driving force for expansion of } \\
\text { adaptation }\end{array}$ & $\begin{array}{l}\text { Existence of societal organizations (NGO's, lobby groups, think tanks) that } \\
\text { had adaptation as part of their agenda/portfolio }\end{array}$ \\
\hline $\begin{array}{l}\text { Various organizations developing normative arguments for } \\
\text { greater government involvement in adaptation }\end{array}$ & Reports, academic papers, conferences, meetings, symposia \\
\hline $\begin{array}{l}\text { Groups pressure government to expand action-development of } \\
\text { narratives calling for broader intervention }\end{array}$ & $\begin{array}{l}\text { Policy briefs, petitions, open letters, media articles/editorials, public } \\
\text { demonstrations }\end{array}$ \\
\hline Govt. acknowledges groups engaging them in dialogue & $\begin{array}{l}\text { Meetings, public hearings, response letters to groups, speeches by govt. } \\
\text { official or politicians }\end{array}$ \\
\hline Internal dialogue in govt. on courses of action to pursue & $\begin{array}{l}\text { Inter-ministerial meetings, steering groups, committees, parliamentary } \\
\text { debate, policy papers, new legislation or rules }\end{array}$ \\
\hline Outcomes of govt. actions put up for public review & $\begin{array}{l}\text { Public consultations, publication of meeting minutes, publication of govt. } \\
\text { decisions }\end{array}$ \\
\hline
\end{tabular}

Table 2 Assumptions and possible evidence for the growth of adaptation policy through Elitism

\begin{tabular}{|c|c|}
\hline Assumptions & Possible evidence \\
\hline \multicolumn{2}{|l|}{ Elitism } \\
\hline $\begin{array}{l}\text { Adaptation was not an issue of public concern-lack of broad civil } \\
\text { discourse, limited number civil societal organizations working on } \\
\text { adaptation }\end{array}$ & $\begin{array}{l}\text { No interest groups developing knowledge, no reports, papers, } \\
\text { meetings, symposia, etc. }\end{array}$ \\
\hline $\begin{array}{l}\text { Adaptation work was being discussed and developed by a small } \\
\text { number of identifiable organizations or individuals inside and outside } \\
\text { government }\end{array}$ & Identifiable policy community \\
\hline $\begin{array}{l}\text { Knowledge on expansion of adaption generated within identifiable } \\
\text { policy community }\end{array}$ & $\begin{array}{l}\text { Reports and papers attributed to a small handful of authors. Meeting } \\
\text { and conferences with limited number of actors. Meetings attended by } \\
\text { the same actors }\end{array}$ \\
\hline $\begin{array}{l}\text { Within government, adaptation restricted to a single office or a handful } \\
\text { of senior officials }\end{array}$ & $\begin{array}{l}\text { Proposed regulations, rules and legislation receive little public scrutiny } \\
\text { or debate and sponsorship can be attributed back to particular } \\
\text { individuals or a single office }\end{array}$ \\
\hline $\begin{array}{l}\text { Proposed government outcomes materially or ideologically benefit } \\
\text { members of the policy community, e.g., insurance and construction } \\
\text { companies }\end{array}$ & $\begin{array}{l}\text { A limited number of companies received financial benefits as a result } \\
\text { of new government policy, e.g., expected annual costs to insurance } \\
\text { companies would decrease or increase in business for construction } \\
\text { companies }\end{array}$ \\
\hline
\end{tabular}

while varied, is rather evenly dispersed throughout the sample. In five countries, we find that there is "significant emergence," five countries with "moderate emergence," and four countries showing "limited" policy field emergence. Only the UK shows "highly significant" emergence on the scale we have constructed.

\section{Influence of factors}

Considering the sample of countries as a whole and making no distinction as to the degree of the policy field, we looked to see which factors (pluralism, elitism, institutionalism) (if any) dominated and the difference in scores between the factors. Working on a scale of 1-5, we see that elite activity scored the highest with an average reported score of 3.43 (13\% above the mean of 3 ), followed by pluralism with 3.20 and institutionalism with 2.90 (see column "All" in Table 5).

However, the overall difference between the scores for each factor was not greatly significant, with elitism scoring 7.2\% higher than pluralism, and pluralism scoring $9.4 \%$ higher than institutionalism. The greatest difference between scores was elitism versus institutionalism marked by an $18 \%$ difference. These scores suggest that, even though elite activity would appear to be the most influential in the emergence of adaptation as a policy field for the entire group and indeed an "important factor" in its own right, all of the factors come into play given their score's close proximity to each other and the mean. It should be noted, however, that if we look beyond the average score for elitism, eight countries ranked elite activity with a score of 4.00 or above. The average appears to be somewhat 
Table 3 Assumptions and possible evidence for the growth of adaptation policy through Institutionalism

\begin{tabular}{|c|c|}
\hline Assumptions & Possible evidence \\
\hline \multicolumn{2}{|l|}{ Institutionalism } \\
\hline $\begin{array}{l}\text { Adaptation evolved out of preexisting related policy fields such } \\
\text { climate change mitigation, land use planning, disaster control or } \\
\text { water management }\end{array}$ & $\begin{array}{l}\text { Early documents, reports and discussion on adaptation would be linked } \\
\text { to or embedded in other policy field documentation. Experts in other } \\
\text { fields began working on adaptation. Adaptation on the meeting } \\
\text { agendas of other policy fields }\end{array}$ \\
\hline $\begin{array}{l}\text { Magnitude of problem perceived too large for related policy fields to } \\
\text { solve. New narratives created on the inability of policy fields to solve } \\
\text { climate change problems }\end{array}$ & $\begin{array}{l}\text { Documents, meetings and speeches questioning capabilities of other } \\
\text { related policy fields to deal with newly perceived climate problems. } \\
\text { The practices and procedures of the fields offer no answer to } \\
\text { adaptation problematique }\end{array}$ \\
\hline $\begin{array}{l}\text { Normative understanding or agreement inside and outside government } \\
\text { that problem should be addressed }\end{array}$ & $\begin{array}{l}\text { Declarative documents and statements calling for new government and } \\
\text { non-government institutions for adaptation }\end{array}$ \\
\hline $\begin{array}{l}\text { New institutional arrangements emerge from related preexisting policy } \\
\text { fields that begin to address problem pressure }\end{array}$ & $\begin{array}{l}\text { People and resources from other related policy fields would be shifted } \\
\text { to and involved in new so called adaptation venues }\end{array}$ \\
\hline
\end{tabular}

Table 4 Distribution of policy field scores by country and degree of emergence

\begin{tabular}{|c|c|c|c|c|c|c|c|}
\hline \multicolumn{2}{|c|}{$\begin{array}{l}\text { Highly significant PF emergence } \\
.75 \leq \mathrm{PFS} \leq 1\end{array}$} & \multicolumn{2}{|c|}{$\begin{array}{l}\text { Significant PF emergence } \\
.50 \leq \mathrm{PFS}<.75\end{array}$} & \multicolumn{2}{|c|}{$\begin{array}{l}\text { Moderate PF emergence } \\
.25 \leq \mathrm{PFS}<.50\end{array}$} & \multicolumn{2}{|c|}{$\begin{array}{l}\text { Limited PF emergence } \\
0<\mathrm{PFS}<.25\end{array}$} \\
\hline \multirow[t]{5}{*}{ United Kingdom } & 1.00 & Spain & .671 & Portugal & .480 & Germany & .238 \\
\hline & & France & .619 & Belgium & .437 & Norway & .238 \\
\hline & & Lithuania & .571 & Hungary & .437 & Sweden & .198 \\
\hline & & Finland & .567 & Denmark & .397 & Netherlands & .159 \\
\hline & & Switzerland & .500 & Austria & .286 & & \\
\hline
\end{tabular}

Table 5 Factor scores sorted by degree of policy field emergence in all countries

\begin{tabular}{llllll}
\hline & All & Highly significant PF emergence & Significant PF emergence & Moderate PF emergence & Limited PF emergence \\
\hline Pluralism & 3.20 & 3.67 & 2.90 & 3.30 & 3.33 \\
Elitism & 3.43 & 4.00 & 3.56 & 3.20 & 3.43 \\
Institutionalism & 2.90 & 2.67 & 2.43 & 3.31 & 3.01 \\
\hline
\end{tabular}

skewed by the responses from Finland and Norway, each giving elitism a 2.00. If these countries are removed, the average score increases to 3.78. Also, no other factors received a score of 4.00 or above from any country (see Table 6).

Looking specifically at the scoring of factors as applied to the different categorization of policy field emergence (Table 6 above), the scores differ in some degree from each other under each category and the group as a whole. Looking first at the category of "highly significant PF emergence," we find again elitism scoring the highest with 4.00 , followed by pluralism at 3.67 and institutionalism at 2.67. It should be noted that this category is represented by only one country, the UK. Despite this, the ranking of factors is the same for countries showing "significant" policy field emergence $(n=5)$, with elitism scoring at 3.56, pluralism 2.90 and institutionalism 2.43. The scores for pluralism and institutionalism are the lowest in this group, as compared to the others, and well below the average for the entire group of the 15 countries.

For countries showing "moderate" signs of PF emergence, the ranking of scores is quite different. Here, we find institutionalism scoring the highest at 3.31 (a $14 \%$ difference from the average for the entire set of countries) pluralism at 3.30 and elitism at 3.20. Admittedly, there is only a miniscule difference between the scores for pluralism and institutionalism, suggesting that both are of equal importance for this group. Also for this group, the difference in importance of elitism from the other factors is very small, just $3 \%$. For those countries showing "limited" signs of PF emergence $(n=4)$, the ranking pattern for scores of elitism, pluralism and institutionalism repeats itself, respectively, 3.43, 3.33 and 3.01. Interestingly, the score for elitism in this group is the same as the entire dataset average while pluralism and institutionalism score higher here than the full dataset average. 
Table 6 Scores for each factor behind policy field emergence by individual country

\begin{tabular}{lllll}
\hline Country & Normalized PF score & Pluralism & Elitism & Institutionalism \\
\hline Austria & 0.286 & 3.03 & 3.63 & 2.47 \\
Belgium & 0.437 & 3.67 & 3.00 & 2.00 \\
Denmark & 0.397 & 2.33 & 4.00 & 3.17 \\
Finland & 0.567 & 3.00 & 2.00 & 2.67 \\
France & 0.619 & 3.67 & 4.80 & 2.00 \\
Germany & 0.238 & 3.67 & 3.00 & 2.67 \\
Hungary & 0.437 & 2.77 & 3.00 & 3.17 \\
Lithuania & 0.571 & 2.33 & 4.00 & 3.17 \\
Netherlands & 0.159 & 3.73 & 4.70 & 3.10 \\
Norway & 0.238 & 2.57 & 2.00 & 3.43 \\
Portugal & 0.480 & 3.33 & 4.00 & 3.67 \\
Spain & 0.671 & 2.33 & 4.00 & 2.00 \\
Sweden & 0.198 & 2.83 & 4.00 & 3.17 \\
Switzerland & 0.500 & 3.17 & 3.00 & 2.33 \\
United Kingdom & 1.000 & 3.67 & 4.00 & 2.67 \\
\hline
\end{tabular}

\section{Discussion and conclusion}

This article opened with two broad lines of inquiry. First, recognizing that adaptation is emerging into a policy field in multiple European countries, we sought to quantify its degree as a policy field in nation states based upon a derived policy field score. What we found is that out of the 27 countries analyzed, one country shows "high significance" of adaptation as a policy field, five "significant" signs, five "moderate" signs, and four "limited" signs based upon our model. This would suggest that institutional order, substantive authority and substantive expertise are beginning to coalesce in varying degrees around adaptation. Second, we sought to explore conceptually and analytically how and if various factors representing different families of state-centered political science theories might explain the emergence of adaptation as a policy field in countries. What we observe is that for the entire sample of 15 countries, elite activity appears to be the most dominant factor driving its emergence. However, when looking at the countries in light of the degree of emergence, the results are not uniform as institutional change appears more dominant for those countries showing "moderate" signs of PF emergence.

Emergence of adaptation as a policy field: discussion and future directions

As stated above, the existence, and we might say, extent of adaption as a policy field in a particular country could have important implications for the practice and delivery of adaptation policy. As Massey and Huitema (2013) argue, where policy fields are more mature the problems/issues the field addresses will, in all likelihood, be dealt with in a systematic and structured manner rather than ad hoc. This is because of greater institutional capacity, a greater degree of authority, money, stability and civic attention being brought to bear on the issue. Also, more generally with an eye toward the study of public policy, they note that new policy fields can foster new forms of governance, including new and innovative instruments never seen before (see also Jordan et al. 2003). With this in mind, a number of questions come to the fore when looking at the variation of the degree of emergence in our dataset. First, is adaptation actually being carried out more effectively in those countries with a higher PF score? Second, is there evidence of new forms of governance and new instruments brought about by adaptation activity and is there variation among countries with different PF scores? Lastly, we might ask whether adaptation "effectiveness" can actually be measured considering that many of the policies implemented are in expectation of projected climate change impacts. Ford and King (2013), while not using the term "effectiveness" explicitly, put forward a conceptual framework to assess what they call "adaptation readiness" or a country's level of preparedness to respond to climate change impacts. An interesting line of research would be to apply their framework across the range of countries in our dataset to see, indeed, if countries showing a higher significance of PF emergence differ in terms of "readiness," from those countries showing limited PF emergence.

\section{Influence of factors}

Looking at our data, we might say that no one factor or lens heavily dominates the discussion on adaptation's emergence as a policy field. While elite activity appears to be the most important factor for the entire dataset, and for 
three out of the four degrees of PF emergence (highly significant, significant, and limited), pluralism is a close second in terms of importance for the entire set, as well as for three out of the four degrees of emergence (highly significant, moderate and limited). Curiously for moderate $\mathrm{PF}$ emergence, we find that elitism scores the lowest and institutionalism the highest, the only group to display such results. How then might we interpret these scores? Should the group of moderate PF emergence be seen as an outlier? On the one hand, we might dismiss this group as such. On the other hand, if we regard adaptation as a policy field emerging in phases (it began as a nonexistent PF then gradually moved along through each stage to reach maturity), then the following narrative can be hypothesized.

In phase one, when adaptation first began to emerge, it was an issue largely being pushed for and promoted by elite policy communities and/or top political officials and policy advisors. They were in effect the spark and the engine to start promoting adaptation as more than just a policy issue, advocating for institutional change so as to create new norms, rules and entities to support their vision. In phase two, when adaptation reached a level of moderate emergence, institutional change previously advocated by elites begins to be implemented and its effects pronounced on the new field's expansion. This could account for institutionalism being the highest ranked factor among this group of countries. In phase three, where we see significant PF emergence, new institutions are established and elite activity once again becomes significant. Here, elites begin evaluating changes taking place, while exerting pressure to see that the changes they advocated for are being successfully implemented. When adaptation reaches a level of high significance (the final phase), the broader network that evolved around adaptation begin to recognize and acknowledge the efforts elites invested into adaptation, not only at its onset but throughout its emergence. In short, we might hypothesize the dynamics of adaptation's emergence as a PF as such: (Phase 1) advocating and promoting institutional change by elites; (Phase 2) implementation of institutional change; (Phase 3) evaluation and oversight of institutional change by elites; (Phase 4) acknowledgment and recognition of elite's effort to enact policy change.

Such a hypothesis, however, is not complete without a fuller treatment of the factors of pluralism and institutionalism. Given that all the countries observed are liberal democratic societies (13 are EU Member States), we might assume that elite policy communities are not entirely divorced from the public they serve and that they actively seek feedback on the policy changes they promote. As such, even though we hypothesize that it was elites that drove adaptation's expansion, their actions were largely supported (or at least not opposed) by their constituencies.
Therefore, pluralist activity might be seen as the bedrock on which the policy field is being built. This in turn could explain the reported scores for the pluralist factors. As for the scores related to institutional versus elite factors, with the exception of those countries showing moderate $\mathrm{PF}$ emergence, we might say that the institutions involved in adaptation's emergence are simply the recipients for and the outcomes of decisions made by elite and pluralistic forces. Such an explanation certainly reinforces the concept that institutions themselves lack agency; in such a scenario, this conclusion is plausible based upon the data. That said, this hypothesis needs to be tested with a larger dataset.

Limitations and future directions: exploring other factors for policy field emergence

While our research design only allowed us to focus on exploring three state-centered political science theories, another possible lens to be explored in future research is Public Choice theory and the role it might have played in adaptation's emergence. Public Choice relies upon the application of economic market theory to explain political and social behavior. Under this theory, government policy is enacted to correct for imbalances or failures in the market. Given that a policy field is in large part a government sponsored entity closely linked to the economy, we might assume that under a strict interpretation of public choice the creation of a policy field was an act to regulate and control for market failure (Majone 1994). Therefore, the expansion of adaptation from a policy issue to a policy field is a government response to address some form of (1) information failure, (2) positive or negative externality and/or (3) provisioning of public goods.

Another aspect not mentioned in our research is the role of the EU. Despite having constrained our analysis to the national level, our study does focus on Europe. Given then the changes in governance brought about by the increasing influence of the EU (see Jordan and Schout 2006), the greater degree of interconnectedness between Member States, and the EU's concerted effort to promote adaptation across the Union, it would prove interesting for future work to include the EU's role into the scenarios of pluralism, elitism, institutionalism (and public choice).

Finally, even though this research focused on exploring the factors through which adaptation might have emerged as a policy field, future research should also focus on explaining why or why not it is emerging as a policy field. A broad brush answer might be related to problem pressure or the perceived severity of climate impacts, and a country's ability to effectively respond. As such we might postulate that countries with a higher degree of a policy field might have had higher climate-related damage costs from extreme weather events (floods, fires, storms) than 
those with a lower degree. However, looking at the per capita damage costs for each group of countries from 2000 to 2013, we find that that while the UK (highly significant PF emergence) had the highest cost per capita at $\$ 352$ USD, the lowest was for countries showing significant signs of PF emergence, with \$235 USD. Costs for countries with moderate and limited signs of PF emergence were $\$ 318$ USD and \$267 USD, respectively. ${ }^{3}$ The relative similarity of the costs across all groups of countries and the lack of a discernible pattern to the costs suggest that other factors are at work. These might include the publicity or visibility afforded to extreme weather events as opposed to the actual cost of the events or the frequency at which the events occur.

\section{Conclusions}

Our work represents the first conceptual and empirical attempt to hypothesize how policy fields might emerge. By cracking the door open with our broad brushstroke analysis, we hope to lay the foundations for future work that is deeper and more refined in its investigation, not only of policy field emergence but equally climate change adaptation. The study of policy change is too often limited to changes within fields. By expanding our focus toward field emergence, we are hoping to capture a completely different dynamic of governance as it relates to large-scale policy change. In relation to adaptation, given climate change has been characterized as one of the greatest challenges of the twenty-first century, how governments choose to govern adaptation will significantly influence their ability to respond to climate pressures. Studying what and how countries have done thus far can offer guidance for those just beginning to undertake adaptation.

Acknowledgments We would like to thank Francisco Estrada, Hans de Moel, Wouter Botzen and Laurens Bouwer for their generous help in understanding statistical and economic principles.

Open Access This article is distributed under the terms of the Creative Commons Attribution License which permits any use, distribution, and reproduction in any medium, provided the original author(s) and the source are credited.

\section{References}

Bauer A, Feichtinger J, Steurer R (2012) The governance of climate change adaptation in ten OECD countries: challenges and approaches. J Environ Planning Policy Manage 14(3):279-304

\footnotetext{
3 Costs were calculated using damage costs as reported on EMDAT (http://www.emdat.be/)with average population from 2004 to 2013 as reported on Eurostat.
}

Baumgartner FR, Jones BD (2009) Agendas and instability in American politics. 2nd edn. The University of Chicago Press, Chicago

Ben-Nun P (2008) Respondent fatigue. In: Lavrakis P (ed) Encyclopedia of survey research methods. Sage Publications, London

Birkland TA (2011) An introduction to the policy process: theories, concepts, and models of public policy making. ME Sharpe Inc, London

Bulpitt J (1986a) Continuity, autonomy and peripheralization: the anatomy of the center's statecraft in England. In: Layton-Henry Z, Rich P (eds) Race, government and politics in Britain. Palgrave Macmillan, New York

Bulpitt J (1986b) The discipline of the new democracy; Mrs. Thatcher's domestic statecraft. Political Studies 34:19-39

Burstein P (1991) Policy domains: organization, culture, and policy outcomes. Annu Rev Sociol 17:327-350

Colgan JD, Keohane RO, Van de Graaf T (2011) Punctuated equilibrium in the energy regime complex. Rev Int Org 7(2):117-143. doi:10.1007/s11558-011-9130-9

Contestabile M (2014) A new policy field. Nat Clim Change 4:954

Dahl RA (1967) Pluralist democracy in the United States: conflict and consent. Rand McNally, Chicago

Dryzek JS, Dunleavy P (2009) Theories of the democratic state. Palgrave Macmillan, New York

Dupiuis J, Biesbroek GR (2013) Comparing apples and oranges? The dependent variable problem in comparing and evaluating adaptation policies. Glob Environ Change 13(6):1476-1487

Evans M (2006) Elitism. In: Hay C, Lister M, Marsh D (eds) The state: theories and issues. Palgrave Macmillan, New York

Ford JD, King D (2013) A framework for examining adaptation readiness. Mitig Adapt Stratg Glob Change. doi:10.1007/s11027013-9505-8

Ford JD et al (2013) How to track climate change adaptation: a typology of approaches for national-level application. Ecol Soc $18(3): 40$

Giddens A (1984) The constitution of society. Polity Press, Cambridge

Goodin RE (2009) The oxford handbook of political science. Oxford University Press, Oxford

Hall PA (1993) Policy paradigms, social learning, and the state the case of economic policymaking in Britain. Comp Polit 25(3):275-296

Hay C, Lister M, Marsh D (2006) The state: theories and issues. Palgrave Macmillan, New York

Howlett M, Ramesh M, Perl A (2009) Studying public policy: policy cycles and policy subsystems, vol Third. Oxford University Press, Toronto

Jochim AE, May PJ (2010) Beyond subsystems: policy regimes and governance. Policy Stud J 38(2):303-327

Jordan A, Huitema D (2014) Policy innovation in a changing climate: sources, patterns and effects. Glob Environ Change. doi:10.1016/ gloenvcha.2014.09.005

Jordan A, Schout A (2006) The coordination of the European union: exploring the capacities of networked governance. Oxford University Press, Oxford

Jordan A, Wurzel RKW, Zito AR (2003) 'New' instruments of environmental governance patterns and pathways of change. Environmen Polit 12(1):1-24

Keskitalo E (ed) (2010) Developing adaptation policy and practice in Europe: multi-level governance of climate change. Springer, Berlin

Kingdon JW (1984) Agendas, alternatives, and public policies. Harper Collins, New York

Knoke D (2004) The sociopolitical construction of national policy domains. In: Henning $\mathrm{CHC}$, Melbeck C (eds) Interdisziplinäre 
sozialforschung: theorie und empirische anwendungen. Campus, Frankfurt, pp 81-96

Laumann EO, Knoke D (1987) The organizational state: social choice in national policy domains. University of Wisconsin Press, London

Lowndes V (2002) Institutionalism. In: Marsh D, Stoker G (eds) Theory and methods in political science, vol Second. Palgrave Macmillan, London

Majone G (1994) The rise of the regulatory state in Europe. In: Miller WC, Wright V (eds) The state in Western Europe: retreat or redefinition?. F. Cass, London

Marsh D, Rhodes RAW (1992) Policy networks in British government. Clarendon Press, Gloucestershire

Massey E, Huitema D (2013) The emergence of climate change adaptation as a policy field: the case of England. Reg Environ Change 13(2):341-352

Massey E, Biesbroek GR, Huitema D, Jordan A (2014) Climate policy innovation: the adoption and diffusion of adaptation policies across Europe. Glob Environ Change. doi:10.1016/j. gloenvcha.2014.09.002

May PJ, Sapotichne J, Workman S (2006) Policy coherence and policy domains. Policy Stud J 34(3):381-403

Mills WC (1956) The power elite. Oxford University Press, Oxford

Neufeldt H, Jochem E, Hinkel J, Huitema D, Massey E, Watkiss P, Lonsdale K (2009) Climate policy and inter-linkages between adaptation and mitigation. In: Hulme M, Neufeldt $\mathrm{H}$ (eds)
Making climate change work for us. Cambridge University Press, Cambridge, pp 3-30

Ostrom E (1986) An agenda for the study of institutions. Public Choice 48(1):3-25

Peters BG, Pierre J (2006) Handbook of public policy. Sage Publications, Washington

Peters BGuy, Pierre J, King DS (2005) The politics of path dependency: political conflict in historical institutionalism. J Politics 67(4):1275-1300

Real-Dato J (2009) Mechanisms of policy change: a proposal for a synthetic explanatory framework. J Comp Policy Anal Res Pract 11(1):117-143

Sabatier PA (2007) Theories of the policy process. Westview Press, Boulder

Sabatier PA, Jenkins-Smith H (1993) Policy change and learning: an advocacy coalition approach. Westview Press, Boulder

Schaffrin A, Sewerin S, Seubert S (2014) The innovativeness of national policy portfolios. Environ Polit 23(5):860-883

Schmidt V (2006) Institutionalism. In: Hay C, Lister M, Marsh D (eds) The state: theories and issues. Palgrave Macmillan, London

Williams R (2009) Exogenous shocks in subsystem adjustment: the credit crunch and Canadian banking regulation. J Pub Policy 29(1):29-53

Young OR (2002) The institutional dimensions of environmental change: fit, interplay, and scale. MIT Press, Boston 